\title{
Cost-effectiveness analysis of antiretroviral therapy in a cohort of HIV-infected patients starting first-line highly active antiretroviral therapy during 6 years of observation
}

\author{
This article was published in the following Dove Press journal: \\ Patient Related Outcome Measures \\ 17 February 2015 \\ Number of times this article has been viewed
}

\section{Franco Maggiolo' \\ Giorgio L Colombo ${ }^{2,3}$ \\ Sergio Di Matteo ${ }^{3}$ \\ Giacomo M Bruno 3 \\ Noemi Astuti' \\ Elisa Di Filippo' \\ Giulia Masini' \\ Claudia Bernardini' \\ 'Division of Infectious Diseases, Azienda Ospedaliera Papa Giovanni XXIII, Bergamo, Italy; ${ }^{2}$ University of Pavia, Department of Drug Sciences, Pavia, Italy; ${ }^{3}$ SAVE Studi Analisi Valutazioni Economiche, Milan, Italy}

Correspondence: Giorgio L Colombo SAVE Studi Analisi Valutazioni Economiche, Via Previati 74,

20149 Milan, Italy

Tel +390248519230

Fax +390273960369

Email giorgio.colombo@savestudi.it
Objectives: Costs may play a role in deciding how and when to start highly active antiretroviral therapy (HAART) in a naïve patient. The aim of the present study was to assess the costeffectiveness of treatment with HAART in a large clinical cohort of naïve adults to determine the potential role of single-tablet regimens in the management of patients with human immunodeficiency virus (HIV). An incremental cost-effectiveness ratio analysis was performed, including a quality-adjusted life year approach.

Results: In total, 741 patients (females comprising 25.5\%) were retrospectively included. The mean age was 39 years, the mean CD4 cell count was 266 cells/ $\mu \mathrm{L}$, and the mean viral load was 192,821 copies $/ \mathrm{mL}$. The most commonly used backbone was tenofovir + emtricitabine (77.6\%); zidovudine + lamivudine was used in $10 \%$, lamivudine + abacavir in $3 \%$, and other nucleoside reverse transcriptase inhibitor (NRTI) or NRTI-free regimens in $9.4 \%$ of patients. NNRTIs were used in $52.8 \%$ of cases, boosted protease inhibitors in $44.1 \%$, and unboosted protease inhibitors and integrase inhibitors in $0.7 \%$ and $2.4 \%$, respectively. Starting therapy at CD4 $>500$ cells $/ \mu \mathrm{L}$ and CD4 $351-500$ cells $/ \mu \mathrm{L}$ rather than at $<201$ cells $/ \mu \mathrm{L}$ was the more cost-effective approach. The same consideration was not true comparing current indications with the possibility to start HAART at any CD4 value (eg, $>500$ cells per $\mu \mathrm{L}$ ); in this case, the incremental cost-effectiveness ratio value was $€ 199,130$ per quality-adjusted life year gained, a higher value than the one suggested in guidelines. The single-tablet regimen (STR) invariably dominated any other therapeutic approach. Sensitivity analysis was performed, and starting right away with an STR was cost-effective even when compared with therapeutic strategies contemplating STR as simplification.

Conclusion: By integrating clinical data with economic variables, our study offers an estimate of the cost-effectiveness of the various first-line treatment strategies for patients infected with HIV and provides significant evidence to be used in future prospective pharmacoeconomic evaluations.

Keywords: cost-effectiveness, quality-adjusted life years, highly active antiretroviral therapy, single-tablet regimen

\section{Introduction}

Combination highly active antiretroviral therapy (HAART) plays a key role in mitigating the human immunodeficiency virus (HIV)/acquired immune deficiency syndrome (AIDS) epidemic by reducing morbidity and mortality. ${ }^{1-3}$ According to international guidelines, ${ }^{4-6}$ all adults with HIV infection should be offered HAART regardless of CD4 cell count, either because of recent observational data indicating 
that any patient may benefit from HAART or on the basis of epidemiologic results stressing that the risk of transmission of the virus is lower in those receiving antiretrovirals than in naïve patients. ${ }^{7,8}$ If there is no CD4 cell count threshold at which starting therapy is contraindicated, the strength of the recommendation and the quality of the evidence supporting initiation of therapy increase as the CD4 cell count decreases because of considerations related to specific clinical conditions, possible drug-drug interactions and toxicities, limits in patient compliance/adherence, and the risk of emergence of resistance that may limit the long-term effectiveness of HAART. $^{7}$ The recent development of the single-tablet regimen (STR), ie, one pill once a day, has been an important development in the optimization of antiretroviral regimens. ${ }^{5}$ Such optimization has the potential to improve long-term adherence, virologic efficacy, clinical outcomes, and patient quality of life.$^{6-9}$ The development of HAART represents one of the most remarkable accomplishments in medical history. The goal of HAART is to reduce viral replication to below the limit of detection of standard clinical assays. A relevant unresolved issue is the CD4 cell count at which HAART should be started in patients with asymptomatic infection. Current guidelines indicate a 500 cells $/ \mu \mathrm{L}$ threshold, but, in many instances this threshold has been questioned and the concept that HAART should be offered to any person infected with HIV irrespective of his/her immunological status is supported by many clinicians. ${ }^{3-6}$ However, even in developed countries, the problem of costs for national health services may play a role in deciding how and when to start HAART in a naïve patient.

\section{Patients and methods}

The aim of the present study was to assess the cost-effectiveness of different treatment strategies in a large clinical cohort of naïve HIV-infected adults to identify the potential role of STR in the management of HIV infection. This was a single-center cohort study in adults diagnosed with HIV infection between January 2006 and June 2012. All patients diagnosed at our center within that period were included. Data were collected from the clinical electronic database (Netcare; Healthware SpA, Naples, Italy) and included demographic characteristics, blood HIV-RNA level and CD4 count before HAART, number and type of HAART regimens, total duration of HAART exposure, HIV-RNA level and CD4 cell counts over time (two determinations per year). The study analyzed the cost and effectiveness of the first HAART dose for HIV patients, through 6 years analysis. After being entered into the analysis and receiving one of the antiretroviral regimens, the patient could slide through eight health states, defined by the variation of CD4 cell counts and HIV-RNA levels, one acquired immune deficiency syndrome state, and one death state. Overall, the analysis was performed according to the intent-to-treat approach: a patient was considered to be on a given HAART regimen according to his/her baseline treatment, but in the case of treatment change/discontinuation, drug costs were calculated accordingly. To define use of STR, because of prescribing indications in Europe, we considered several different scenarios in the sensitivity analysis: starting with tenofovir + emtricitabine + efavirenz and then switching to STR; starting with any efavirenz-based once-daily regimen and switching to STR; and starting with any HAART regimen and then switching to STR.

\section{Resource utilization and cost- effectiveness analysis}

Resource consumption associated with the patients was calculated on the basis of direct health care costs that included antiretroviral treatment (HAART), hospitalizations (Diagnosis-Related Group), visits and laboratory examinations to monitor HIV infection, specific additional examinations (eg, magnetic resonance, tomography, endoscopy), and chronic non-antiretroviral therapies (eg, lipidlowering, antidiabetic, and antihypertensive agents). These data allowed us to calculate the direct costs and effectiveness of each drug regimen. Cost data were collected from the clinical electronic database (Netcare). The analysis was carried out from the point of view of the Italian National Healthcare Service (Servizio Sanitario Nazionale). The effectiveness indicators considered were utility scores as evaluated by quality-adjusted life years (QALYs). ${ }^{10}$ The utility values associated with the eight health states identified by the CD4 cell count ${ }^{11}$ published in the study by Simpson et al were calculated using the EuroQol-5 Dimensions questionnaire (http://www.euroqol.org). For CD4+ values $>500$ cells $/ \mu \mathrm{L}$, the utility score was 0.9460 ; for CD4+ values of $351-500$ cells/ $\mu \mathrm{L}$, the utility score was 0.9330 ; for $\mathrm{CD} 4+$ values of $201-350$ cells/ $\mu \mathrm{L}$, the utility score was 0.9310 ; and for CD4+ values $<200$ cells $/ \mu \mathrm{L}$, the utility score was 0.8300 . The incremental cost-effectiveness ratio (ICER) was used to evaluate cost-effectiveness. The ICER analysis was performed in order to calculate cost per QALYs gained. ICER provides the additional resources that have to be used to achieve the additional benefit. When the value of a new therapeutic option needs to be assessed, the ICER is calculated as the difference in cost divided by the difference in effect between alternatives. ${ }^{11}$ 


\section{Statistical analysis}

The analysis was undertaken using Microsoft Excel 2010 (Microsoft Corporation, Redmond, WA, USA). Descriptive results are presented as the mean \pm standard deviation and percentage with $95 \%$ confidence interval. All tests were two-sided and a $P$-value less than 0.05 was regarded as being statistically significant. Finally, we performed a one-way sensitivity analysis in order to evaluate if the switch to STR from other treatment regimens results in changes in costs and QALYs versus the base case scenario.

\section{Results}

\section{Baseline characteristics and patient disposition}

A total of 741 subjects who were initially diagnosed with HIV infection between January 2006 and June 2012 and started HAART were included in the present analysis (Table 1). Most of the subjects were Italian ( $72 \%$ ), with $13 \%$ of cases being of sub-Saharan origin. Twenty-six percent of the patients were females. At diagnosis the mean age was $39 \pm 10$ years, the mean CD4 cell count was $266 \pm 229$ cells $/ \mu \mathrm{L}$, and the mean viral load was $192.821 \pm 344.744$ copies/mL. At presentation, $24.8 \%$ of patients had an acquired immune deficiency syndrome-defining event according to the 1995 Centers for Disease Control and Prevention revised classification.

Table I Characteristics of enrolled patients

\begin{tabular}{|c|c|c|}
\hline Variable & $\begin{array}{l}\text { Number } \\
\text { or mean }\end{array}$ & $\begin{array}{l}\text { Percentage } \\
\text { or SD }\end{array}$ \\
\hline \multicolumn{3}{|l|}{ Sex } \\
\hline Male & 552 & 74.5 \\
\hline Female & 189 & 25.5 \\
\hline Age (years) & 39 & 10 \\
\hline \multicolumn{3}{|l|}{ Origin } \\
\hline Italy & 537 & 72.5 \\
\hline Sub-Saharan Africa & 103 & 13.9 \\
\hline South America & 33 & 4.4 \\
\hline Europe & 30 & 4.0 \\
\hline North Africa & 22 & 2.9 \\
\hline Other & 16 & 2.3 \\
\hline \multicolumn{3}{|l|}{ CDC classification } \\
\hline Group AI & 99 & 13.4 \\
\hline Group C & 195 & 26.3 \\
\hline CD4+ T-cells (cells/mm³) & 266 & 299 \\
\hline Patients with CD4+ T-cells & 216 & 29.1 \\
\hline \multicolumn{3}{|l|}{$<100$ cells $/ \mathrm{mm}^{3}$} \\
\hline Baseline HIV-RNA (copies/mL) & $|92,82|$ & 344,744 \\
\hline \multicolumn{3}{|l|}{ Patients with baseline HIV-RNA } \\
\hline$>100,000$ copies $/ \mathrm{mL}$ & 297 & 40.1 \\
\hline$>500,000$ copies $/ \mathrm{mL}$ & 84 & $1 \mathrm{I} .4$ \\
\hline
\end{tabular}

Abbreviations: CDC, Centers for Disease Control and Prevention; HIV, human immunodeficiency virus; SD, standard deviation.
Thirty patients (4\%) died during the follow-up period, $85(12 \%)$ were lost to follow-up, and 17 (2\%) moved to other centers; therefore, 609 patients ( $82 \%$ ) continued to be treated. The mean Kaplan-Meier estimate of follow-up was 67 months (95\% confidence interval, 65-69).

\section{Drug use and additional costs}

Most commonly used backbone was tenofovir + emtricitabine (77.6\% of cases), while zidovudine + lamivudine was used in $10 \%$ of subjects, lamivudine + abacavir in $3 \%$, and other nucleoside reverse transcriptase inhibitor (NRTI) combinations or NRTI-free regimens in $9.4 \%$. Most therapies were non-NRTIs, (52.8\%). The third drug in the combination was a boosted protease inhibitor in $44.1 \%$ of cases, and unboosted protease inhibitors and integrase inhibitors accounted for the remaining $0.7 \%$ and $2.4 \%$, respectively. The most common first-line regimens are reported in Figure 1, that describes persistence (proportion on HAART therapies during followup) with specific drug combinations. Persistence is defined as any change in the initial regimen for whatever reason. Overall, statistical significance $(P<0.0001)$ was observed. In head-to-head comparisons, tenofovir + emtricitabine + ritonavir-boosted lopinavir persistence resulted significantly shorter. Overall, 256 patients (34.5\%) received STR at some point in their therapeutic path. A total of 192 hospital admissions were registered for the whole cohort over the study follow-up period. The reasons for hospital admission are reported in Figure 2, and the costs of each hospital admission were calculated according to the Italian reimbursement system (Diagnosis-Related Group). The most common chronic non-antiretroviral therapies were for hypertension $(3.3 \%$ of patients) and diabetes (1.5\%).

\section{Cost-effectiveness analysis}

The cost-effectiveness analysis was based on a utility score (QALYs) according to variation in CD4 cell counts and HIV-RNA levels. Application of HAART induced a constant increment of mean CD4 cell count in treated patients that paralleled the increasing percentage (over time) of patients with a blood HIV-RNA level below the detection limit (50 copies/mL, Figure 3).

The first analysis performed considered whether the CD4 level at which HAART was started did affect costeffectiveness. Patients were categorized according to their CD4 count, consistent with the current guideline recommendations for starting HAART. Starting therapy at a CD 4 count above 351 cells $/ \mu \mathrm{L}$ was more costeffective than starting it at a much lower CD4 threshold 


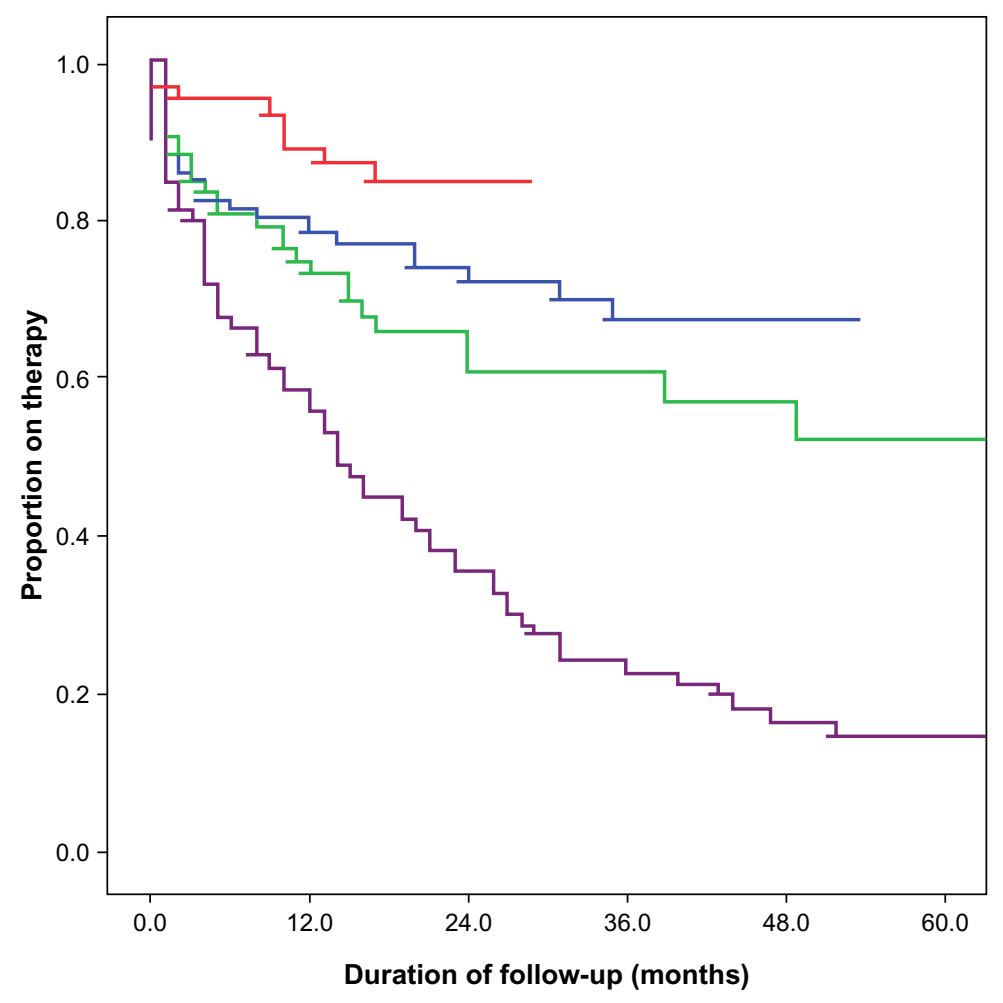

Figure I Characteristics of enrolled patients: proportion on highly active antiretroviral therapies during follow-up period. Abbreviations: TDF, tenofovir; FTC, emtricitabine; LPV, lopinavir; DRV, darunavir; ATV, atazanavir; RTV, ritonavir-boosted.

( $<201$ cells $/ \mu \mathrm{L}$, Table 2$)$. The same was not true comparing current indications with the possibility to start HAART at any $\mathrm{CD} 4$ value (eg, $>500$ cells $/ \mu \mathrm{L}$ ). In this case, the mean yearly cost per patient ranged from $€ 8,405(351-500 \mathrm{CD} 4 / \mu \mathrm{L}$ group) to $€ 9,105$ (>500 CD4/ $\mu \mathrm{L}$ group); the increment in
QALYs was very limited 0.004 (from 0.939 to 0.943 ), resulting in an ICER of $€ 199.130$, far above the threshold to define the intervention as cost-effective.

On the other hand, when different HAART regimens were considered, STR invariably dominated over any other
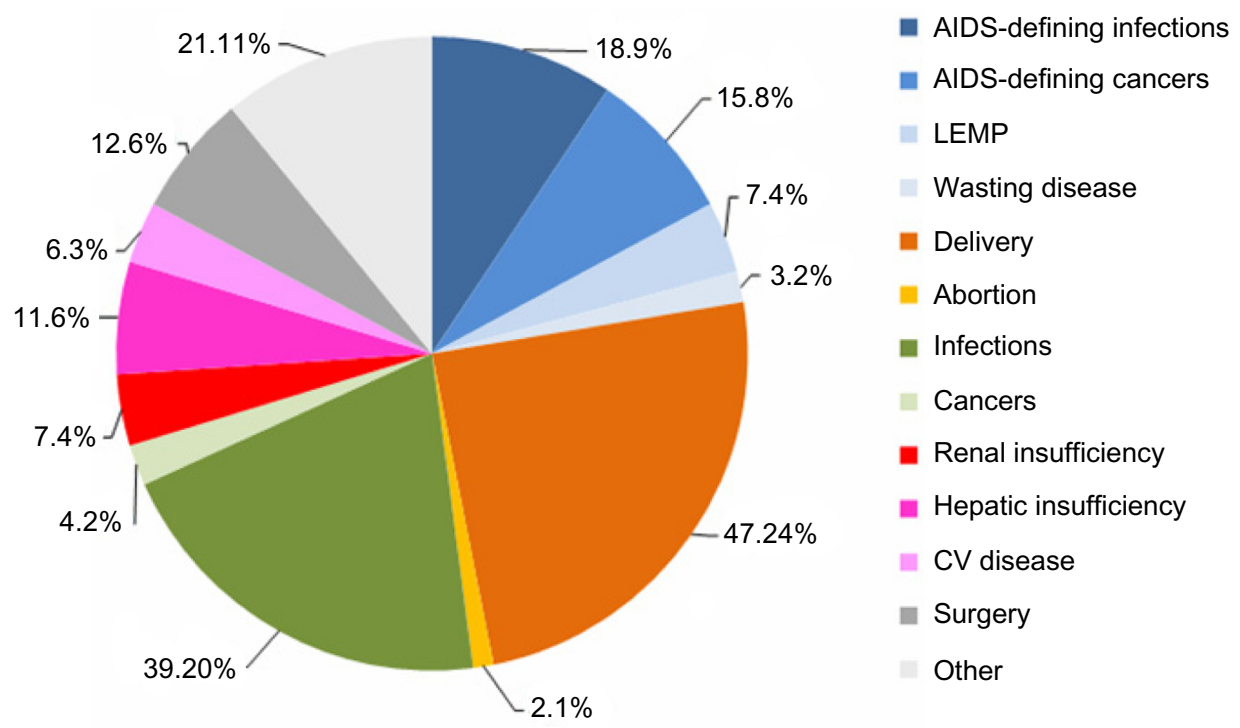

Figure 2 Characteristics of enrolled patients: causes of hospital admission during period of observation.

Abbreviations: AIDS, acquired immune deficiency syndrome; CV, cardiovascular; LEMP, progressive multifocal leukoencephalopathy. 


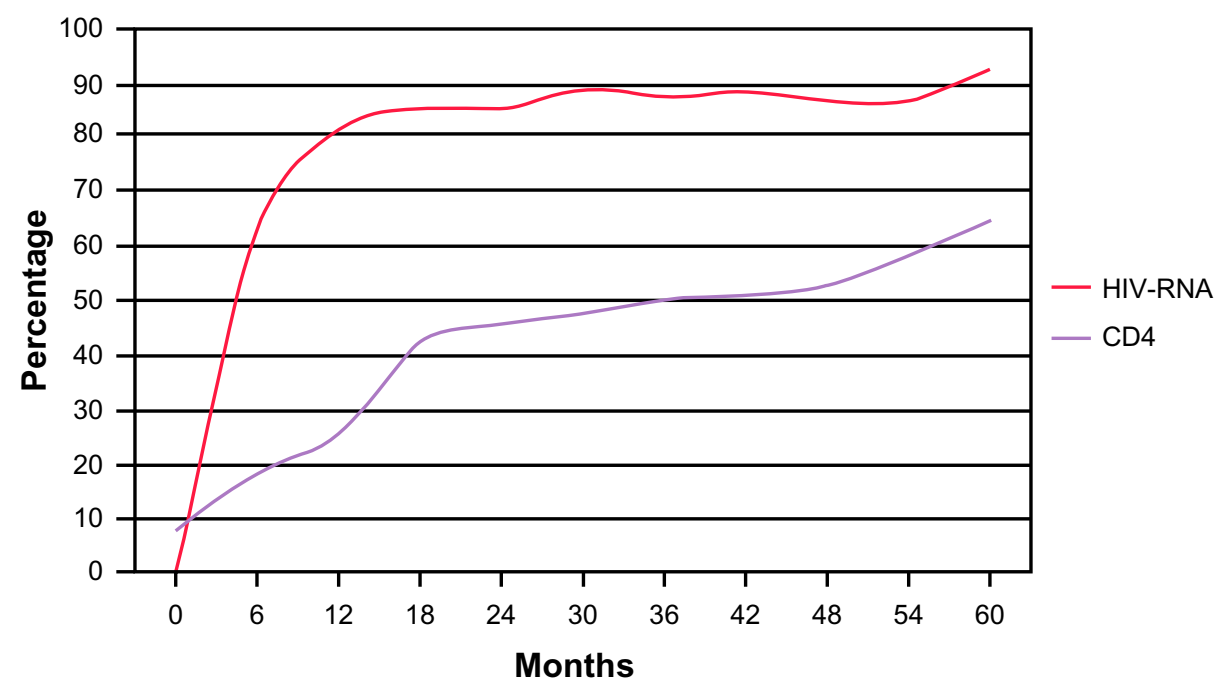

Figure 3 Virologic and immunologic response to highly active antiretroviral therapies during follow-up period, proportion of patients with a viral load $<50$ copies $/ \mathrm{mL}$ and a CD4 count $>500$ cells per $\mu \mathrm{L}$.

Abbreviation: HIV, human immunodeficiency virus.

therapeutic approach, independent of the definition of STR (Table 3). If we consider in our analysis all patients treated once daily with efavirenz-based HAART who then switched to STR and all patients on any HAART regimen who then switched to STR we can see less cost and better effectiveness (QALYs) in all patients switched to STR, which as a simplification option becomes the dominant strategy when compared with other options (Figure 4).

\section{Discussion}

Delayed initiation of HAART has been correlated with an increased risk of death, and unexpectedly, with lower tolerability of antiretroviral medication. ${ }^{1}$ In addition to the clinical advantages at the individual level, early HAART may be a tool to control the spread of the HIV epidemic. . $^{8,12}$ Initiating HAART at lower CD4 counts has been shown to be associated with increased costs. ${ }^{13,14}$ Our data confirm these findings and indicate that, from the economic point of view, current indications regarding when to start HAART are cost-effective. However, we found that increasing the
CD4 threshold for starting HAART above 500 cells $/ \mu \mathrm{L}$ only minimally improved QALYs, so did not justify the incremental cost of such a strategy. A possible limitation of this interpretation is that we evaluated costs only on the basis of individual outcomes and quality of life, but the picture might change when including population effects. ${ }^{12}$ As an example, widespread early initiation of HAART could influence the prevalence of highly infective subjects and change the trend of the epidemic, lowering the number of new infections and therefore making such an approach more cost-effective. Although "when" to start HAART yielded conflicting results, in our experience the "how" question showed a clear-cut picture.

The options for initial therapy in treatment-naïve adults with confirmed drug-susceptible virus continue to expand, with development of new drugs and coformulations. ${ }^{4}$ Because therapy is expected to be continued indefinitely, the optimal choice of the initial regimen is based on several characteristics having as a reference either the patient (convenience, potential toxicities, and tolerability), the virus (maximal,

Table 2 Cost-effectiveness analysis for baseline pre-HAART CD4 counts

\begin{tabular}{|c|c|c|c|c|c|c|c|c|}
\hline \multirow{2}{*}{$\begin{array}{l}\text { Baseline } \\
\text { CD4 }\end{array}$} & \multirow{2}{*}{$\begin{array}{l}\text { Patients } \\
\text { (n) }\end{array}$} & \multirow{2}{*}{$\begin{array}{l}\text { C } \\
\text { Mean cost } \\
\text { per patient }\end{array}$} & \multirow{2}{*}{$\begin{array}{l}\text { E } \\
\text { Mean QALYs } \\
\text { per patient }\end{array}$} & \multirow{2}{*}{$\begin{array}{l}\text { C/E } \\
\text { Mean cost } \\
\text { per QALY }\end{array}$} & \multirow{2}{*}{$\begin{array}{l}\frac{\Delta \mathrm{C}}{\text { Delta }} \\
\text { cost }\end{array}$} & \multirow{2}{*}{$\begin{array}{l}\Delta \mathrm{E} \\
\text { Delta } \\
\text { QALYs }\end{array}$} & \multirow{2}{*}{$\begin{array}{l}\frac{\Delta C / \Delta E}{I C E R ~ Q A L Y s} \\
\text { versus CD4 }<20 \text { I }\end{array}$} & \multirow{2}{*}{$\begin{array}{l}\Delta \mathrm{C} / \Delta \mathrm{E} \\
\text { ICER QALYs versus } \\
\text { CD4 35I-500 }\end{array}$} \\
\hline & & & & & & & & \\
\hline$<201$ & 331 & $€ 8,938$ & 0.915 & $€ 9,77 ।$ & - & - & - & - \\
\hline $201-350$ & 142 & $€ 8,185$ & 0.937 & $€ 8,736$ & $-€ 753.36$ & 0.022 & Dominant & - \\
\hline $35 I-500$ & 60 & $€ 8,405$ & 0.939 & $€ 8,948$ & $-€ 532.86$ & 0.025 & Dominant & - \\
\hline$>500$ & 39 & $€ 9,105$ & 0.943 & $€ 9,658$ & $€ 167.42$ & 0.028 & $€ 5,954$ & $€ 199,130$ \\
\hline
\end{tabular}

Note: "Dominant" less costly and more effective.

Abbreviations: HAART; highly active antiretroviral therapy; ICER, incremental cost effectiveness ratio; QALYs, quality-adjusted life years. 
Table 3 Cost-effectiveness analysis for different treatments

\begin{tabular}{|c|c|c|c|c|c|c|c|}
\hline Treatment & $\begin{array}{l}\text { Patients } \\
\text { (n) }\end{array}$ & $\begin{array}{l}\mathrm{C} \\
\text { Mean cost } \\
\text { per patient }\end{array}$ & $\begin{array}{l}\text { E } \\
\text { Mean QALYs } \\
\text { per patient }\end{array}$ & $\begin{array}{l}\text { C/E } \\
\text { Mean cost } \\
\text { per QALYs }\end{array}$ & $\begin{array}{l}\frac{\Delta \mathrm{C}}{\text { Delta }} \\
\text { cost }\end{array}$ & $\begin{array}{l}\frac{\Delta \mathrm{E}}{\mathrm{Delta}} \\
\text { QALYs }\end{array}$ & $\begin{array}{l}\Delta \mathrm{C} / \Delta \mathrm{E} \\
\text { ICER } \\
\text { QALYs }\end{array}$ \\
\hline TDF + FTC + EFV $\rightarrow$ switch STR & 219 & $€ 7,701$ & 0.931 & $€ 8,274$ & - & - & - \\
\hline $\mathrm{Pl} / \mathrm{rtv}$ OD-based HAART & 164 & $€ 10,976$ & 0.927 & $€ \mid \mathrm{I}, 838$ & $€ 3,275$ & -0.004 & Dominated \\
\hline $\mathrm{PI} /$ rtv BID-based HAART & 158 & $€ 10,735$ & 0.923 & $€ 1 \mathrm{I}, 636$ & $€ 3,033$ & -0.008 & Dominated \\
\hline Other HAART & 191 & $€ 8,772$ & 0.930 & $€ 9,435$ & $€|, 07|$ & -0.001 & Dominated \\
\hline
\end{tabular}

Note: "Dominated" more costly and less effective.

Abbreviations: ICER, incremental cost-effectiveness ratio; TDF, tenofovir; FTC, emtricitabine; EFV, efavirenz; STR, single-tablet regimen; QALYs, quality-adjusted life years; BID, twice daily; OD, once daily; HAART, highly active antiretroviral therapy; PI, protease inhibitor; RTV, ritonavir-boosted.

lifelong suppression of HIV replication to prevent emergence of resistance, facilitate optimal immune recovery, and improve health), or the health care system (sustainability). Treatment simplification has been considered as a way to address most of the variables with regard to the patient and the virus.

Parienti et $\mathrm{al}^{15}$ investigated treatment adherence with once-daily regimens in a meta-analysis that included eleven randomized controlled trials with a total of 3,029 subjects. Adherence rates were slightly higher with once-daily regimens $(+2.9 \%$; 95\% confidence interval, $1.0-4.8 ; P=0.003)$ than with twice-daily regimens. The effect was more relevant for HAART-naïve patients and when all medications were taken once daily. More recent studies comparing once-daily regimens with more frequently dosed regimens continue to support the positive impact of once-daily regimens on HAART adherence. ${ }^{16-21}$ Pill burden is also an important factor affecting both adherence and quality of life. ${ }^{9}$ Dosing frequency and pill burden have been identified as relevant parameters for treatment persistence. ${ }^{22}$ Distinct from but related to medication adherence, persistence reflects the duration of time from initiation to discontinuation of therapy, and can be measured at the regimen or patient level. In developed countries, improved regimen persistence, or durability, has been observed with regimens dosed once daily and containing fewer pills. ${ }^{23}$ Although the clinical benefit of simple HAART regimens has been demonstrated, data on cost-effectiveness are still lacking and mostly refer to mathematical models or cohort studies with limited follow-up. ${ }^{24-26}$ Our study enrolled a fairly large number of patients who were followed for a consistent period of time. Further, the time frame allowed for eligibility enabled us to exclude patients treated with antiretroviral regimens that are no longer recommended by current guidelines.

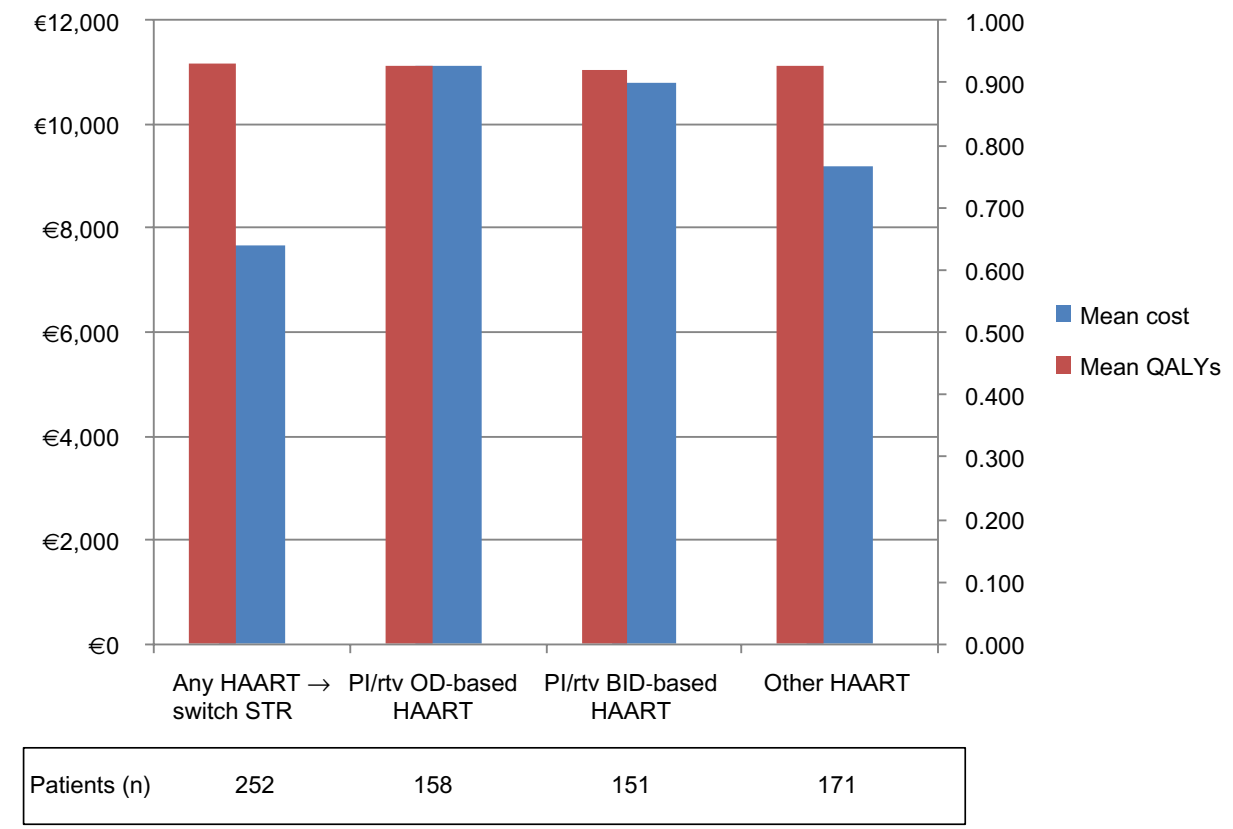

Figure 4 Sensitivity analysis for mean costs and QALYs for any HAART $\rightarrow$ switch STR versus different treatments.

Abbreviations: EFV, efavirenz; STR, single-tablet regimen; QALYs, quality-adjusted life years; BID, twice daily; OD, once daily; HAART, highly active antiretroviral therapy; PI, protease inhibitor; RTV, ritonavir-boosted. 
Under these circumstances, simple, convenient one-pill-a-day regimens can be considered cost-effective ${ }^{27}$ and usually dominate control regimens, making their use worthwhile even on the basis of a budget impact analysis. Use of STR since the beginning of treatment was also cost-effective compared with different switch or simplification strategies.

We recognize that our study has some limitations. The most important one concerns the quality of data entered into the analysis. Parameters such as utility scores are based on studies with a limited time frame and may be inadequate for modeling the lifelong treatment of a chronic disease. As an example, the improvement in quality of life was derived from a clinical study within a 6-month time horizon and was extended to the entire follow-up period. In other cases, the utilities entered into the model had to be derived from different literature sources ${ }^{11}$ dealing with groups of patients and populations that could differ from our cohort, but that were considered as applicable to the Italian population. ${ }^{10}$ For this reason, changes in the utilities deriving from the switch to an STR were examined by a rigorous probabilistic sensitivity analysis which identified their limitations and ranges of variation. Another limitation was the size of the patient sample in this analysis; however, compared with similar research, ${ }^{28,29}$ our sample was 741 versus 474 and 194 patients, and our time horizon was 6 years instead of 4 and 2 years; in spite of these increases in sample size and duration of observation, our pharmacoeconomic analysis still confirms a cost reduction per HIV-infected patient treated with STR versus other regimens. Apart from the abovementioned limitations, the results presented here try to give a pharmacoeconomic answer to the questions of when and how to start HAART. Results such as ours, derived from pharmacoeconomic analysis, need to be coupled with constant monitoring of real practice addressed to recognize the precise economic value of any pharmaceutical innovation or strategy. In spite of its limitations, pharmacoeconomic analysis plays a strategic role when establishing priorities in the allocation of resources. We believe that, by collecting appropriate clinical data and integrating them with economic variables, our study allowed us to obtain a more accurate estimate of the cost-effectiveness ratio of the various first-line treatment strategies for $\mathrm{HIV}$-infected patients and provides significant evidence to be used in future prospective pharmacoeconomic evaluations.

\section{Acknowledgments}

This research was supported by an unrestricted grant from Gilead Sciences Srl, Milan, Italy. The authors are employees of independent research organizations and maintained independent scientific control over the study, including data analysis and interpretation of final results.

\section{Disclosure}

FM has served as a consultant on advisory boards for Boehringer Ingelheim, Bristol-Myers Squibb, Gilead, GlaxoSmithKline, and Tibotec. He has also received lecture fees from Bristol-Myers Squibb, Gilead, GlaxoSmithKline, and Merck Sharp \& Dohme, and has received research and educational grants from Boehringer Ingelheim, Bristol-Myers Squibb, GlaxoSmithKline, Jansen-Cilag, and Roche. GLC has served as a consultant on advisory boards for Takeda, DOC Generici, LEO Pharma, Gilead Sciences, Merck Sharp \& Dohme, Astellas, and Pfizer, and has received research and educational grants from Takeda, Gilead Sciences, Merck Sharp \& Dohme, and LEO Pharma. The other authors report no conflicts of interest in this work.

\section{References}

1. Lundgren JD, Babiker A, El Sadr WM, et al. Inferior clinical outcome of the CD4+ cell count-guided antiretroviral interruption strategy in the SMART study: role of CD4+ cell counts and HIV-RNA levels during follow-up. J Infect Dis. 2008;197:1145-1155.

2. The Antiretroviral Therapy Cohort Collaboration. Life expectancy of individuals on combination antiretroviral therapy in high-income countries: a collaborative analysis of 14 cohort studies. Lancet. 2008;372:293-299.

3. Volberding PA, Deeks SG. Antiretroviral therapy and management of HIV infection. Lancet. 2010;376:49-62.

4. Panel on Antiretroviral Guidelines for Adults and Adolescents. Guidelines for the use of antiretroviral agents in HIV-1-infected adults and adolescents. Department of Health and Human Services. Available from: http://www.aidsinfo.nih.gov/ContentFiles/AdultandAdolescentGL.pdf. Accessed November 27, 2014.

5. Thompson MA, Aberg JA, Hoy JF, et al. Antiretroviral treatment of adult HIV infection: 2012 recommendations of the International Antiviral Society-USA panel. JAMA. 2012;308:387-402.

6. Antinori A, Marcotullio S, Ammassari A, et al. Italian guidelines for the use of antiretroviral agents and the diagnostic-clinical management of HIV-1 infected persons. New Microbiol. 2011;34:109-146.

7. Maltez F, Dorona M, Branco T, et al. Recent advances in antiretroviral treatment and prevention in HIV-infected patients. Curr Opin HIV AIDS. 2011;6 Suppl 1:S21-S30.

8. Cohen MS, Chen YQ, McCauley M, et al; HPTN 052 Study Team. Prevention of HIV-1 infection with early antiretroviral therapy. $N$ Engl J Med. 2011;365:493-505.

9. Airoldi M, Zaccarelli M, Bisi L, et al. One-pill once-a-day HAART: a simplification strategy that improves adherence and quality of life of HIV-infected subjects. Patient Prefer Adherence. 2010;4:115-125.

10. Colombo GL, Di Matteo S, Antinori A, Medaglia M, Murachelli S, Rizzardini G. Economic evaluation of initial antiretroviral therapy for HIV-infected patients: an update of Italian guidelines. Clinicoecon Outcomes Res. 2013;5:489-496.

11. Simpson KN, Luo MP, Chumney E, et al. Cost-effectiveness of lopinavir/ ritonavir versus nelfinavir as the first-line highly active antiretroviral therapy regimen for HIV irtfection. HIV Clin Trials. 2004;5:294-304.

12. Montaner JS, Lima VD, Barrios R, et al. Expanded HAART coverage is associated with decreased population-level HIV-1-RNA and annual new HIV diagnoses in British Columbia, Canada. Lancet. 2010;376: $532-539$. 
13. Oliva-Moreno J, Lopez-Batida J, Serrano-Aguilar P, Perestelo-Perez L. Determinants of health care costs of HIV-positive patients in the Canary Islands, Spain. Eur J Health Econ. 2010;11:405-412.

14. Levy A, Johnston K, Annemans L, Tramarin A, Montaner J. The impact of disease stage on direct medical costs of HIV management: a review of the international literature. Pharmacoeconomics. 2010;28 Suppl 1: $35-47$.

15. Parienti JJ, Bangsberg DR, Verdon R, Gardner EM. Better adherence with once-daily antiretroviral regimens: a meta-analysis. Clin Infect Dis. 2009;48:484-488.

16. Nachega JB, Mugavero MJ, Zeier M, Vitória M, Gallant JE. Treatment simplification in HIV-infected adults as a strategy to prevent toxicity, improve adherence, quality of life and decrease healthcare costs. Patient Prefer Adherence. 2011;5:357-367.

17. Maggiolo F, Ripamonti D, Arici C, et al. Simpler regimens may enhance adherence to antiretrovirals in HIV infected patients. HIV Clin Trials. 2002;5:371-378.

18. Lima VD, Harrigan R, Bangsberg DR, et al. The combined effect of modern highly active antiretroviral therapy regimens and adherence on mortality over time. J Acquir Immune Defic Syndr. 2009;50:529-536.

19. Sterrantino G, Santoro L, Bartolozzi D, et al. Self-reported adherence supports patient preference for the single tablet regimen (STR) in the current cART era. Patient Prefer Adherence. 2012;6:427-433.

20. Maggiolo F, Ravasio L, Ripamonti D, et al. Similar adherence rates favor different virologic outcomes for patients treated with nonnucleoside analogues or protease inhibitors. Clin Infect Dis. 2005;40:158-163.

21. Deschamps AE, De Graeve V, Van Wijngaerden E, et al. Prevalence and correlates of nonadherence to antiretroviral therapy in a population of HIV patients using medication event monitoring system. AIDS Patient Care STDs. 2004; 18:644-657.
22. Bae JW, Guyer W, Grimm K, Altice FL. Medication persistence in the treatment of HIV infection: a review of the literature and implications for future clinical care and research. AIDS. 2011;25:279-290.

23. Willig JH, Abroms S, Westfall AO, et al. Increased regimen durability in the era of once-daily fixed-dose combination antiretroviral therapy. AIDS. 2008;22:1951-1960.

24. Colombo GL, Di Matteo S, Maggiolo F. Antiretroviral therapy in HIVinfected patients: a proposal to assess the economic value of single tablet regimen. Clinicoecon Outcomes Res. 2013;5:59-68.

25. Rizzardini G, Restelli U, Bonfanti P, et al. Cost of human immunodeficiency virus infection in Italy, 2007-2009: effective and expensive, are the new drugs worthwhile. Clinicoecon Outcomes Res. 2012;4:245-252.

26. Ganguli A, Wang J, Gourley DR. Does combining antiretroviral agents in a single dosage form enhance quality of life of HIV/AIDS patients? A cost-utility study. Res Social Adm Pharm. 2012;8:157-165.

27. Grosse SD. Assessing cost-effectiveness in healthcare: history of the $\$ 50,000$ per QALY threshold. Expert Rev Pharmacoecon Outcomes Res. 2008;8:165-178.

28. Colombo GL, Castagna A, Di Matteo S, et al. Cost analysis of initial highly active antiretroviral therapy regimens for managing human immunodeficiency virus-infected patients according to clinical practice in a hospital setting. Ther Clin Risk Manag. 2014;10:9-15.

29. Rizzardini G, Bonfanti P, Carenzi L, et al. Cost-effectiveness analysis of HIV treatment in the clinical practice of a public hospital in northern Italy. Ther Clin Risk Manag. 2012;8:377-384.
Patient Related Outcome Measures

\section{Publish your work in this journal}

Patient Related Outcome Measures is an international, peer-reviewed, open access journal focusing on treatment outcomes specifically relevant to patients. All aspects of patient care are addressed within the journal and practitioners from all disciplines are invited to submit their work as well as healthcare researchers and patient support groups.

\section{Dovepress}

The manuscript management system is completely online and includes a very quick and fair peer-review system. Visit http://www.dovepress. com/testimonials.php to read real quotes from published authors. 